\title{
COMMENTARY
}

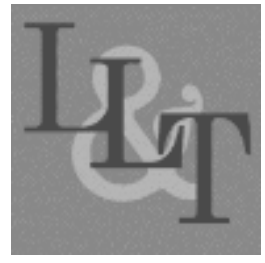

\section{Corpora in language learning and teaching}

\author{
Nina Vyatkina, University of Kansas \\ Alex Boulton, University of Lorraine
}

Keywords: Corpus, Computer-Assisted Language Learning, Language Teaching Methodology, Web-Based Instruction

APA Citation: Vyatkina, N., \& Boulton, A. (2017). Corpora in language learning and teaching. Language Learning \& Technology, 21(3), 1-8. Retrieved from http://lt.msu.edu/issues/october2017/commentary.pdf

\section{Introduction}

Corpora, in the sense of large, systematically organized electronic collections of texts, came to be used in language learning and teaching shortly after they emerged in their modern form in the 1960s. Whereas originally, most pedagogical applications were of indirect nature with corpus-based studies informing the contents of textbooks and reference tools (e.g., word lists, dictionaries, and grammars), the interest in more direct applications - when either teachers or learners interacted with corpora themselves - started to grow from the 1980s. The first report on a direct application of corpus-derived examples in a language classroom was published by McKay (1980) and was followed by a few other largely descriptive or theoretical publications in the same decade. However, the birth of both a distinct teaching method and a distinct subfield of language teaching research is generally identified with work by Johns in the late 1980s and 1990s. Drawing on computer science, he gave this revolutionary approach the name of data-driven learning (DDL) and outlined its several pedagogical benefits-most famously in a special issue of the English Language Research Journal co-edited with Philip King (Johns \& King, 1991). The first DDL research results were published mostly as exploratory case studies and reflection pieces, with empirical research taking off and growing exponentially after the turn of the century.

Since its inception, the DDL field has accumulated a substantial body of publications. An overview can be gained from a number of research synthesis articles: both narrative reviews (e.g., Boulton, in press; Chambers, 2007b; Römer, 2011) and recent meta-analyses (e.g., Boulton \& Cobb, 2017; Mizumoto \& Chujo, 2015). Whereas the former cover the breadth of the field with its multitude of topics and methodologies as well as the chronology of its development, the latter provide a secondary statistical analysis of research results from quantitative studies. Publications have appeared in refereed journals and edited volumes from major publishers, but also as theses and dissertations, online publications, and articles in less well-known journals and conference proceedings. Several journals have also dedicated special issues to DDL: the English Language Research Journal (Johns \& King, 1991), the Journal of English for Academic Purposes (Thompson, 2007), Language Learning \& Technology (Tribble \& Barlow, 2001), and ReCALL (Boulton \& Pérez-Paredes, 2014; Chambers, 2007a). Published research attests to the versatility of DDL applications. It has been applied in second and foreign language teaching contexts in many countries and at diverse educational institutions with learners at different proficiency levels, has included both work with teacher-prepared corpus-derived materials and direct corpus searches by learners, and has focused on various linguistic elements, most frequently vocabulary and grammar, but also pragmatics and discourse. The meta-analysis by Boulton and Cobb (2017) of quantitative studies published through June 2014 confirms that DDL is, overall, an effective and efficient approach to language teaching, inasmuch as it leads to significant learning gains and is better than many traditional teaching methods for various instructional targets. Furthermore, perception studies show that many students enjoy DDL as a novel learning approach.

These overall positive results do not imply, however, that all studies have come to uniform conclusions. 
DDL's effectiveness seems to be considerably moderated by a variety of context-related, participantrelated, and linguistic variables, many of which are still underexplored. From the pedagogical perspective, DDL has been shown to be beneficial because it provides learners with attested usage examples, helps learners develop analytical and problem-solving skills, and promotes learner autonomy. However, the approach has also been associated with certain limitations. One obvious obstacle is the non-transparent user interface of many available corpora which were designed by corpus linguists for specialists like themselves, and not with teachers and students in mind, requiring considerable levels of linguistic and technological sophistication. Another limitation is that corpus examples, while being "genuine," may not be authentic for language learners (Widdowson, 2000) because they are taken out of a larger context and often come from texts that are of little interest or relevance to learners. Finally, from the teacher's point of view, many DDL activities require considerable preparation time, and ready-made teaching materials are few and far between. These limitations have hindered mainstream acceptance of DDL in language teaching practice. In summary, despite generally encouraging DDL research findings over a period of time, this field of inquiry is still developing and has a rich potential for the future. This consideration provided the impetus for the current publication. Since the only Language Learning \& Technology special issue on DDL was published back in 2001, the present guest editors decided that the time has now come to revisit the topic, especially considering the relative paucity of DDL publications in North American journals and presses.

\section{This Issue}

\section{Scope}

For this special issue, we solicited reports on theoretically grounded and methodologically rigorous empirical studies of language learning processes or outcomes in DDL contexts using expert- or nativespeaker as well as learner corpora. We were open as to the specific DDL format employed in pedagogical interventions: it could be hands-on (i.e., include direct explorations of corpora by learners) or hands-off (i.e., include indirect applications with teacher-prepared corpus-based materials), or it could present any combinations of the two formats. We especially welcomed proposals that aimed to fill existing research gaps by reporting on the use of new DDL technologies (e.g., multimodal corpora or corpus tools beyond concordancers), the effectiveness of different DDL types, specific DDL effects on language learning, longitudinal studies, integration of DDL instruction modules into regular curricula, as well as languages other than English, instructional contexts other than a university, and teachers other than DDL researchers. We did not consider submissions containing only descriptions of corpora, software, or pedagogical procedures without presenting in-depth empirical data. We also did not accept studies that analyzed or compared linguistic data from various types of corpora without examining teaching and learning processes and outcomes.

The response to our call for papers exceeded our expectations with 67 initial abstract proposals. 17 were invited to submit a full paper, of which seven were finally accepted for publication-approaching the maximum that the journal can accommodate in a single issue. We would like to note that it was a struggle to select from many excellent submissions and we had to make our decisions with an eye to achieving a broad topic coverage. There are, however, several aspects on which we did not obtain a wide representation: all papers in this issue focus on the acquisition of English with university students as participants via concordancing of written or transcribed corpora. Nevertheless, the contributions to this issue expand the empirical DDL research base by targeting various language learning contexts (English as a first, second, or foreign language), proficiency levels (from low-intermediate to advanced), and instructional targets (grammar, vocabulary, pragmatics, discourse, reading, writing, pedagogy). A brief overview of these studies is presented in the next section.

\section{Article Overviews}

In the first study of this special issue, Bardovi-Harlig, Mossman, and Su explore the effect of corpus-based instruction on learner oral production of pragmatic routines. The novelty of this study is its focus on 
pragmatics and speaking skills, a relative rarity in DDL research. Undergraduate English as a second language (ESL) students at a U.S. university worked with transcripts of academic speech from the open access MICASE corpus (Simpson, Briggs, Ovens, \& Swales, 2002). The treatment consisted of four lessons and the tasks included noticing pragmatic routines associated with three speech acts (agreement, disagreement, and self-clarification) and practice in using these routines in learners' own oral conversations. The participants were divided into three groups: one group worked with teacher-prepared paper-based corpus experts, the second group searched corpora directly to find relevant excerpts, and the third group did not receive any pragmatics instruction. All groups took a pre-test and an immediate post-test that consisted of a computer-based simulated discussion. The results showed that all three groups used speech acts and pragmatic routines more appropriately and accurately on the post-test. However, both experimental groups improved significantly more than the control group on the use of the routines. As far as the use of speech acts is concerned, only the hands-off groups that worked with teacher-prepared materials showed a statistically significant advantage over the control group, but not the hands-on, direct corpus search group. The authors attribute this to the nature of teacher-prepared examples: they presented carefully selected, clearly delineated speech acts, whereas direct corpus searches yielded longer stretches of text with speech acts not explicitly marked. It turned out to be challenging for the students to identify speech acts, especially ones consisting of multiple speaker turns, in these texts. The authors conclude that both DDL approaches are beneficial for L2 pragmatics learning but that hands-on DDL may be less appropriate for learning certain pragmatic targets. This study is significant not only because of its rare focus on oral pragmatic routines but also because the DDL treatments were administered by the regular teachers, in contrast to the majority of DDL interventions delivered by researchers themselves.

In the next article, Cotos, Link, and Huffman explore the use of their Research Writing Tutor (RWT) - a web-based platform that contains a corpus of 900 published research articles in 30 disciplines annotated for rhetorical moves - by US graduate students in an academic writing course. The authors situate their study within the framework of genre-based writing theories, thus bringing L2 writing research and DDL together. This study is similar to the one by Bardovi-Harlig et al., in that it also focuses on a relatively rare research target in DDL research, namely, discourse moves. The instructional intervention included students' direct searches of the RWT corpus with the task of noticing and writing down language patterns characteristic of specific genre moves. The data included students' written responses to awareness-raising questions (noticing data) and two drafts of their own research papers - the second draft being a revision based on the corpus input (production data). The researchers employed an embedded mixed-methods design by first qualitatively analyzing and coding student writing for linguistic material characteristic of certain moves and then quantitatively comparing frequencies of the coded categories. The results showed that genre move patterns noticed by the students were overwhelmingly representative of expert academic writing, thus demonstrating high potential of DDL for awareness raising. Furthermore, the noticing results were similar for both native speaker (NS) and non-native speaker (NNS) novice writers. In contrast, the production data showed that DDL led to significant improvements in the NNS but not the NS writing, although there was no difference between the groups on their first drafts. The authors also provide a fine-grained, qualitative analysis of specific language patterns noticed and used by individual students to express individual moves and steps within moves. They conclude that DDL is beneficial for genre learning and academic writing for both NSs and NNSs, although they acknowledge that their quantitative results need to be considered with caution due to a small sample size, especially of the NS data.

Whereas the first two studies were conducted in an ESL context (with Cotos et al. also including novice NS data), the remaining five articles report on DDL interventions in countries where English is spoken and learned as a foreign language. Hadley and Charles explore the use of DDL in an extensive reading program at a Japanese university. This study is novel because of its focus on reading skills as well as its target learner population-low-intermediate learners, rather than more advanced learners. The participants were divided into two groups, with both engaging in extensive reading from graded readers and traditional vocabulary learning activities (e.g., keeping a vocabulary log, writing sentences with the new words, etc.). Beyond that, the DDL group completed exercises with concordances from the graded reader corpus, whereas the 
comparison group performed more traditional activities. Like Cotos et al., Hadley and Charles employed a mixed-methods design, combining a quantitative analysis of reading speed and vocabulary knowledge data with a qualitative analysis of learner perception data elicited via a personal construct repertory grid instrument adopted from psychology. The results of the study show that both groups improved significantly on all measures, but the improvement of the comparison group was greater. The qualitative analysis helps shed light on this result: the learners found hands-on DDL challenging and time-consuming, despite the considerable scaffolding provided by the instructors, which resulted in negative attitudes toward the approach and the lack of effort invested in completing the corpus tasks. Hadley and Charles conclude that DDL needs to be carefully tailored to learner proficiency levels and appropriately softened for novice and intermediate learners.

The focus of the next three studies is more representative of DDL research in general: they all explore the use of lexico-grammatical constructions in learner writing and the role of DDL concordancing on enhancing this use. Li's study is situated in a graduate course at a Chinese university. Students were divided into two groups with the same learning goals: one exposed to a traditional, deductive method of teaching verbpreposition collocations, and the other engaged in inductive DDL, namely in direct searches of the BNC and COCA (Davies, 2008). Both groups wrote academic essays before the course, immediately after the course, and a month later. The results showed that both groups improved on their use of collocations and this improvement was retained on the delayed post-test. The learning was manifested in the increased number of academic collocations as well as improved accuracy and naturalness of these collocations. However, although the groups were not different from each other on the pre-test, the DDL group improved significantly more on both post-tests. The difference between groups had a very large effect size, which strongly supports the benefit of DDL for the development of productive use of collocations in English for academic purposes (EAP) writing, at least for graduate students with advanced English as a foreign language (EFL) proficiency.

What sets apart the study by Han and Shin is their use of the web as corpus and Google as a concordancer. EFL students at a Korean university participated in a 4-day workshop on teaching Google search techniques (i.e., using quotation marks and a wildcard). Participants were tested before and after each of the three training sessions - the first focusing on the use of articles, the second on collocations, and the third on paraphrasing. The test items included correction of inaccurate or infelicitous expressions and translation of sentences from Korean into English. The results were significant for improvement in article use, but not significant for collocations and paraphrasing. The authors attribute the variable success to the participants' English proficiency level-intermediate compared to, for example, the advanced learners in Li's study. They also conclude that, apparently, more teacher guidance is needed for DDL with this learner population. Nevertheless, the learners found the learned search techniques useful, which showed potential for their future independent use of the web as a corpus. Additionally, the authors provide a qualitative analysis of Google-assisted revisions in learners' own writing.

Ackerley also investigates DDL effects on EFL writing, although her focus was on opinion survey reports instead of academic essays. What is truly impressive in her study is the sample size: two cohorts consisting of 240 and 233 Italian university students, respectively. The linguistic target in this study was, like in two other studies discussed above, collocations. The first cohort learned how to write survey reports with a traditional method, which included conventional vocabulary and collocation exercises as well as the perusal of a number of reports written by experts and pre-selected by the teacher. The second learner cohort, enrolled in the same course during the next year, was engaged in DDL. They worked with a corpus of expert (NS) reports as well as with a learner corpus that comprised reports written by the previous cohort of their fellow students. The exercises included both hands-off and hands-on DDL activities with concordances and frequency data. Both groups wrote their own survey reports at the end of the module. Ackerley conducted a fine-grained analysis of the use of specific collocations in all three corpora: the expert corpus, the control learner corpus, and the DDL learner corpus. The author concludes that the DDL group used a wider range of genre-appropriate (i.e., expert-like) collocations and produced a lower number of stock phrases. She also found that the learners benefited more from hands-off than from hands-on exercises. This finding can be 
explained by the participants' proficiency level, since the intermediate students may have found the vast input resulting from direct corpus searches overwhelming.

In the final article in this issue, Leńko-Szymańska tackles the topic of developing corpus literacy among pre-service language teachers and analyzes corpus-based teaching projects prepared by participants in Poland as a result of a semester-long course. For the projects, participants compiled their own small, specialized corpora from texts found on the web and prepared teaching materials based on those corpora. The researcher analyzed the projects qualitatively with an eye to whether participants had developed three types of DDL-related skills: technical, corpus-linguistic, and pedagogical. She concludes that technical skills were developed to a moderate extent, but there was little evidence of developed corpus-linguistic and DDL-pedagogical skills. In the light of her findings, the author proposes to reconsider the approach to teacher education courses that aim at DDL pedagogy. Table 1 summarizes the main design characteristics of all studies.

Table 1. Design Features of the Studies in This Issue

\begin{tabular}{|c|c|c|c|c|c|c|}
\hline \multirow{3}{*}{$\begin{array}{l}\text { Authors } \\
\text { Bardovi-Harlig, } \\
\text { Mossman, \& Su }\end{array}$} & \multirow{3}{*}{$\begin{array}{l}\text { Focus } \\
\text { Pragmatics, } \\
\text { Speaking }\end{array}$} & \multirow{3}{*}{$\begin{array}{l}\text { Corpora } \\
\text { MICASE (EAP NS } \\
\text { and NNS corpus) }\end{array}$} & \multicolumn{4}{|c|}{ Participants } \\
\hline & & & \multirow{2}{*}{$\begin{array}{l}\text { L2 Setting } \\
\text { ESL }\end{array}$} & \multirow{2}{*}{$\frac{\mathbf{L 1}}{\text { Various }}$} & \multicolumn{2}{|c|}{ UG or G L2 Level } \\
\hline & & & & & UG & $\begin{array}{l}\text { Advanced- } \\
\text { low }\end{array}$ \\
\hline $\begin{array}{l}\text { Cotos, Link, \& } \\
\text { Huffman }\end{array}$ & $\begin{array}{l}\text { Discourse, } \\
\text { Writing }\end{array}$ & $\begin{array}{l}\text { Custom-made NS } \\
\text { EAP corpus }\end{array}$ & ESL, NS & Various & $\mathrm{G}$ & Advanced \\
\hline Hadley \& Charles & $\begin{array}{l}\text { Vocabulary, } \\
\text { Reading }\end{array}$ & $\begin{array}{l}\text { Oxford Bookworm } \\
\text { Graded Readers }\end{array}$ & EFL & Various & $\mathrm{UG}$ & $\begin{array}{l}\text { Intermediate } \\
\text {-low }\end{array}$ \\
\hline $\mathrm{Li}$ & $\begin{array}{l}\text { Collocations, } \\
\text { Lexico- } \\
\text { Grammar, } \\
\text { Writing }\end{array}$ & $\mathrm{BNC}, \mathrm{COCA}$ & EFL & Chinese & $\mathrm{G}$ & Advanced \\
\hline Han \& Shin & $\begin{array}{l}\text { Collocations, } \\
\text { Grammar, } \\
\text { Writing }\end{array}$ & Web as corpus & EFL & Korean & $\mathrm{UG}$ & Intermediate \\
\hline Ackerley & $\begin{array}{l}\text { Collocations, } \\
\text { Writing }\end{array}$ & $\begin{array}{l}\text { Custom-made NS } \\
\text { and learner corpora } \\
\text { (opinion surveys) }\end{array}$ & EFL & Italian & $\mathrm{UG}$ & Intermediate \\
\hline Leńko-Szymańska & $\begin{array}{l}\text { Pedagogy, } \\
\text { Writing }\end{array}$ & $\begin{array}{l}\text { Learner-made NS } \\
\text { corpora (various } \\
\text { topics) }\end{array}$ & EFL & Polish & $\mathrm{G}$ & Advanced \\
\hline
\end{tabular}

Note. $U G=$ undergraduate $;=$ graduate.

\section{Summary and Outlook}

Editing this special issue provided insights into current and likely future directions for DDL. We also received further insight from the DDL colloquium that we organized at the AAAL 2017 conference. The colloquium, which was a namesake of this special issue and where the presentations mainly overlapped with the papers presented here, has sparked a similarly high level of interest among both the audience and numerous academic publishers. There are a number of common trends that emerge from a synthesis of the papers here. First, the focus firmly remains on English as a target language and university contexts, which no doubt reflects real-world needs despite our efforts to encourage a wider variety in this respect. Second, we were very pleased to have received honest and critical reports as our authors did not hesitate to describe 
cases in which DDL turned out not to live up to expectations in all respects. We consider it very important that such reports get published to avoid the file-drawer problem, a serious issue not just in the DDL field but in applied linguistics more broadly and, indeed, in scientific research as a whole. In particular, the studies collected here show that hard DDL may be less helpful than softer versions or traditional teaching methods for learners with lower L2 proficiency (Ackerley; Hadley \& Charles; Han \& Shin); for fuzzy instructional targets like speech acts (Bardovi-Harlig et al.), as opposed to lexico-grammar in particular; and for developing complex pedagogical skills in pre-service teachers within a limited time frame (LeńkoSzymańska). At the same time, hard hands-on DDL is highly effective and efficient for learning very specific instructional targets (e.g., collocations, discourse moves, pragmatic routines) and for more advanced learners (Bardovi-Harlig et al.; Cotos et al.; Li). Third, a major strength of the submissions in this issue is a careful description of the instructional contexts in which DDL interventions were conducted. These descriptions, which helped the authors to explain many of their findings, resulted in a colorful mosaic of various L1s, countries, institutions, and participant profiles represented in this issue. Fourth, we are grateful to our authors for their great efforts toward ensuring the methodological rigor of their studies. The quantitative analyses included very useful effect size statistics, which give a different perspective from the usual significance tests and allow comparisons across studies. The qualitative analyses provided detailed descriptions of the participants and the data. It was also gratifying to see that several authors chose to use mixed designs that combined both quantitative and qualitative analyses or included delayed post-tests and explored long-term DDL effects. Finally, we are glad to see a wide range of instructional targets and language skills represented in these studies, expanding the DDL field beyond the still dominant focus on collocations and writing.

We would like to conclude our commentary by suggesting some directions for future DDL research. First, while English is, doubtlessly and understandably, the most popular target language, we would like to reiterate that more DDL research on other target languages is needed. There are corpora in many world languages, including open access corpora with built-in search and analysis tools, and pedagogical experiments with these corpora would immensely enrich the DDL landscape by providing insights into the applicability of DDL for languages typologically different from English (e.g., inflectional languages; see Vyatkina, 2016a, 2016b). Furthermore, we would like to invite researchers to explore the potential of a wider variety of corpus types (such as the web as corpus, multimodal corpora, parallel corpora) and corpus tools beyond the still prevalent concordancers (e.g., Google as a language search tool, word profiling, timelines, frequency lists, network analysis tools). After all, what the term DDL actually implies is noticing and analyzing language patterns in textual data with the help of electronic tools. Such a broadened understanding of corpora and DDL may help bridge the notorious research-teaching divide and bring more DDL into teaching approaches, manuals, and syllabuses. Furthermore, there is much potential in expanding the collaboration between educators dedicated to DDL and those working to promote digital humanities and other types of digital literacy. The level of computer skills and access to electronic media and tools is constantly growing across learner populations. While current DDL studies, including those in this issue, still show that lower-proficiency learners require substantial scaffolding and assistance, we predict that this gradual overall improvement of computer literacy will lead to increasing success of hands-on DDL even with beginning and intermediate L2 learners. After all, hands-on approaches are the ultimate goal of DDL educators as this promotes learner autonomy and allows for lifelong learning and using corpora as a reference resource beyond the classroom. We acknowledge, however, that the global digital divide (Warschauer, 2003) is not going to disappear in the foreseeable future, so we hope that DDL researchers and educators will develop and promote more open-access hands-on DDL resources as well as paper-based DDL materials for learners with limited access to technology. Methodologically, we would like to encourage DDL researchers to avail themselves of statistical tools that afford multidimensional, multifactorial, dynamic, and longitudinal analyses. Such methods would allow researchers to account for multiple learner and task variables, which are inevitably present in any language learning context, and thus lead to more precise results and richer interpretations of them (Cunnings, 2012). As far as qualitative analyses are concerned, we agree with Levy (2015) that they are most effective when used in combination with quantitative analyses in mixed-methods designs and that their primary goal should be "closing in on 
the learner's experience" (p. 554). Furthermore, future replication studies would strengthen the findings from past DDL research with small sample sizes (see Chun, 2012). Finally, we think that there is much underexplored potential in bringing DDL research more closely together with theories and pedagogical principles of instructed second language acquisition (ISLA). As Boulton notes: "Curiously, perhaps, while many empirical studies refer to theoretical and pedagogical foundations, few seek directly to test [those foundations], and theory has not been a major driving force leading to new practices" (in press). Several studies in this issue have explicitly grounded their research questions in SLA and ISLA theories and have empirically tested specific theoretical principles, and we hope that more future studies will follow suit.

\section{Acknowledgements}

We wish to thank all the authors who submitted their manuscripts. We also want to acknowledge all the reviewers who provided their expert comments and opinions during multiple rounds of revision.

\section{References}

Boulton, A. (in press). Research timeline: Corpora in language teaching and learning. Language Teaching, 50(4). doi: 10.1017/S0261444817000167

Boulton, A., \& Cobb, T. (2017). Corpus use in language learning: A meta-analysis. Language Learning, 67(2), 348-393. doi: 10.1111/lang.12224

Boulton, A., \& Pérez-Paredes, P. (Eds.). (2014). Researching new uses of corpora for language teaching and learning. ReCALL, 26(2). doi: 10.1017/S0958344014000068

Chambers, A. (Ed.). (2007a). Integrating corpora in language learning and teaching. ReCALL, 19(3). doi: $10.1017 /$ S0958344007000134

Chambers, A. (2007b). Popularising corpus consultation by language learners and teachers. In E. Hidalgo, L. Quereda, \& J. Santana (Eds.), Corpora in the foreign language classroom (pp. 3-16). Amsterdam, Netherlands: Rodopi.

Chun, D. (2012). Review article: Replication studies in CALL research. CALICO Journal, 29(4), 591600. doi: 10.11139/cj.29.4.591-600

Cunnings, I. (2012). An overview of mixed-effects statistical models for second language researchers. Second Language Research, 28(3), 369-382. doi: 10.1177/0267658312443651

Davies, M. (2008). The corpus of contemporary American English: 450 Million Words, 1990-Present. Retrieved from http://corpus.byu.edu/coca/

Johns, T., \& King, P. (Eds.). (1991). Classroom concordancing. English Language Research Journal, 4.

Levy, M. (2015). The role of qualitative approaches to research in CALL contexts: Closing in on the learner's experience. CALICO Journal, 32(3), 554-568. doi: 10.1558/cj.v32i3.26620

McKay, S. (1980). Teaching the syntactic, semantic, and pragmatic dimensions of verbs. TESOL Quarterly, 14(1), 17-26.

Mizumoto, A., \& Chujo, K. (2015). A meta-analysis of data-driven learning approach in the Japanese EFL classroom. English Corpus Studies, 22, 1-18.

Römer, U. (2011). Corpus research applications in second language teaching. Annual Review of Applied Linguistics, 31, 205-225. doi: 10.1017/S0267190511000055

Simpson, R. C., Briggs, S. L., Ovens, J., \& Swales, J. M. (2002). The Michigan corpus of academic spoken English. Ann Arbor, MI: The Regents of the University of Michigan. Retrieved from http://quod.lib.umich.edu/m/micase/ 
Thompson, P. (Ed.). (2007). Corpus-based EAP pedagogy. Journal of English for Academic Purposes, 6(4). doi: 10.1016/j.jeap.2007.09.010

Tribble, C., \& Barlow, M. (Eds.). (2001). Using corpora in language teaching and learning. Language Learning \& Technology, 5(3). Retrieved from http://llt.msu.edu/vol5num3/default.html

Vyatkina, N. (2016a). Data-driven learning for beginners: The case of German verb-preposition collocations. ReCALL, 28(2), 207-226. doi: 10.1017/S0958344015000269

Vyatkina, N. (2016b). Data-driven learning of collocations: Learner performance, proficiency, and perceptions. Language Learning \& Technology, 20(3), 159-179. Retrieved from http://lit.msu.edu/issues/october2016/vyatkina.pdf

Warschauer, M. (2003). Technology and social inclusion: Rethinking the digital divide. Cambridge, MA: MIT Press.

Widdowson, H. G. (2000). On the limitations of linguistics applied. Applied Linguistics, 21(1), 3-25.

\section{About the Authors}

Nina Vyatkina is Associate Professor and Chair of the Department of Germanic Languages and Literatures at the University of Kansas. Her research interests include ISLA, corpus-based language learning and teaching, and learner corpus research. Her articles have appeared in leading applied linguistics journals and she serves on the editorial boards of Language Learning \& Technology and International Journal of Learner Corpus Research.

E-mail: vyatkina@ku.edu

Alex Boulton is Professor of English and Applied Linguistics at the University of Lorraine. Research interests relate generally to lexis, language learning, and new technologies, specifically potential uses of corpus linguistics for ordinary teachers and learners (DDL). Editor of ReCALL and on committees for several other journals and associations, he is currently assistant director of the ATILF (Analyse et Traitement Informatique de la Langue Française: UMR 7118-CNRS \& University of Lorraine) and head of its research group Crapel (Didactique des langues et sociolinguistique), as well as assistant director of the first UFR Lansad (faculty of languages for non-specialists) in France.

E-mail: alex.boulton@univ-lorraine.fr 